Article

\title{
Moral Distress and Resilience in the Occupational Therapy Workplace
}

\author{
Annette M. Rivard and Cary A. Brown * \\ Faculty of Rehabilitation Medicine, Department of Occupational Therapy, University of Alberta, Edmonton, \\ AB T6G 2G4, Canada; arivard.ot@gmail.com \\ * Correspondence: cary.brown@ualberta.ca; Tel.: +1-780-492-9545
}

Received: 7 January 2019; Accepted: 2 February 2019; Published: 7 February 2019

check for updates

\begin{abstract}
Healthcare professionals are inherently vulnerable to moral distress due to their frequent work with persons who are suffering or in crisis, in combination with the strong empathic orientation that underpins the very act of care giving. When accompanied by high workloads, deficiencies in management practices such as low recognition, lack of work autonomy, and/or insufficient opportunity for growth and development, persons in caring professions are at an even higher risk of moral distress. There is evidence that professional resilience is effective in mitigating workplace stress. Successful individual-management of moral distress requires attention to the broader institutional conditions under which these difficulties arise. This paper presents findings from 79 occupational therapists in Alberta and Saskatchewan, Canada, who participated in a survey of moral distress and resilience. On a standardized measure of resiliency their scores fell at the lower end of normal. On a standardized measure of moral distress, the highest levels involved issues of: time to do the job properly, deteriorated quality of care, insensitive co-workers, and unrealistic expectations from others. Nearly $50 \%$ reported that they had considered leaving a position due to moral distress. The survey was carried out with the goal of developing a teaching module that included education about moral distress and recommendations for the enhancement of both individual resilience and the construction of resiliency-promoting work environments.
\end{abstract}

Keywords: moral distress; workplace safety; patient safety; resiliency; occupational therapy; healthcare provider

\section{Introduction}

Healthcare professionals are inherently vulnerable to moral distress due to their frequent work with persons who are suffering or in crisis, in combination with the strong empathic orientation that underpins the very act of care giving [1]. For some practitioners, morally distressing occurrences are perceived as just a part of their daily work. For others, the initial distress does not dissipate, but rather reactive distress sets in with lingering consequences [2]. Moral distress occurs when a practitioner recognizes the right course of action but is unable to act ethically because of factors that are perceived to be beyond his/her control [2]. For example, moral distress can result when a healthcare provider knows that a certain treatment will be more effective and less painful for a patient, but, because of resource limitations, they are required to use one that is less effective and causes more pain. Knowingly inflicting more pain, that is technically necessary over a number of episodes, is morally upsetting to people whose professional ethos centers on patient wellbeing and care. Moral distress is typically triggered and shaped by macro level structures that are usually beyond the health professionals' purview [3], and is associated with negative consequences for both individuals (job dissatisfaction, and progressive insensitivity to ethical patient care), and organizations (reduced quality of care, and increased staff turnover) [3]. Unresolved moral distress, with accompanying feelings 
of depletion or powerlessness, can compromise healthcare providers' ability to uphold their ethical standards and diminish the physical and emotional energy needed to fully address patients' needs [3]. This is a critical issue because, in addition to resulting individual health difficulties (such as emotional exhaustion, diminished moral sensitivity, and burnout [3]), there is an increased threat to the safety and wellbeing of patients and co-workers [1,4]. The literature reports a high incidence of nurses resigning from positions and even leaving the profession as a result of moral distress [5]. Increased absenteeism and turnover gives rise to compromised patient care and poorer organizational outcomes due to loss of organizational knowledge, disrupted continuity of care, potential interruption in the implementation of evidence-based practices, and eventually lead to decreased consumer trust in the system. These worrisome consequences notwithstanding, there is evidence that resilience, or the ability to learn and grow from adversity, is effective in mitigating the detrimental effects of workplace stress and moral distress [6,7]. For example, McAllister and McKinnon's research review focused on nursing students, revealed that a number of qualities that foster resiliency (such as social support, problem solving, and communication skills) could be taught. They concluded that teaching resiliency-the ability to bounce back from negative events—was a critical skill that should be addressed in healthcare provider educational programs [7].

Though moral distress is not unique to any one healthcare discipline, members of different professions may experience it for different reasons [5]. While the moral distress experienced by Canadian occupational therapists has been examined [8-10], no study was found that included participants from the Canadian prairies. According to Pauly et al., moral distress is specifically associated with difficulties navigating practice while upholding one's professional values and responsibilities [11]. Research with occupational therapists has indicated that ethical tensions tend to be related to: (a) resource and systemic constraints: e.g., insufficient economic resources to implement quality interventions and to inform practice, and working at a superficial level due to lack of time [12]; (b) upholding ethical principles and values: e.g., being torn between a concern for clients' priorities and those of their healthcare organization; and (c) interpersonal conflicts: e.g., perceptions that one's clinical opinion is not respected, continually having to justify intervention decisions, or when one's opinion frequently differs from the team's resulting in tension between being client-centered and being perceived as delaying discharge $[2,8,9,12,13]$. Moral distress can be experienced concurrently with, and/or lead to, burnout for which organizational risk factors include excessive workload, perceived powerlessness and lack of control over one's work, inability to exercise professional autonomy, perceived inequity, and conflict between individual and organizational values [14].

Encouragingly, some recent research also suggests that moral distress can become a catalyst for personal transformation and growth, and for positive action on the organization's part [3,11]. Aligning with this, resilience is described as the ability to "cope, learn, and grow from difficult experiences" [15], to "healthfully adapt to challenges, stresses, adversity, or trauma" [3], and to "maintain personal and professional wellbeing in the face of on-going work stress and adversity" [2]. Moral resilience encompasses the ability to reframe stressful events as opportunities instead of viewing them as threats and to respond in healthy ways. More specifically, in the event of moral tensions, moral resilience represents "the capacity ... to sustain or restore [one's] integrity in response to moral complexity, confusion, distress, or setbacks" [3]. Recognizing and measuring moral distress is a requisite first step in both mitigating it, and using it as a springboard for action by both practitioners and policy-makers that contributes to the cultivation of resilience.

As a component of a larger project to develop moral distress and resiliency web-based psychoeducational resources, we need to address the gap in research specific to occupational therapists and moral distress. This paper presents survey findings addressing the research question of the prevalence of moral distress, and levels of resilience, among occupational therapists in Alberta and Saskatchewan, Canada. 


\section{Methods}

\subsection{Procedures}

Following institutional ethics approval (blinded for review, Pro00072996), an invitation to participate in an anonymous on-line survey was emailed to all occupational therapists on the Society of Alberta Occupational Therapists (SAOT) and Saskatchewan Society of Occupational Therapists (SSOT) membership lists. Whereas registration with SSOT is mandatory in Saskatchewan $(\mathrm{N}=$ 340) [16], membership with SAOT is voluntary and typically represents about $25 \%$ of the approximately 2200 regulated occupational therapists in Alberta. This means that at a minimum the survey was distributed to 890 therapists in Saskatchewan and Alberta. In the interest of capturing as wide a sample of therapists as possible, SAOT members were asked to share a link to the surveys with as many colleagues as possible. Because of this snow-ball recruitment we cannot determine the exact number of therapists who received the invitation. A reminder was sent approximately three weeks after the first mailing. Participants clicked on a link in the invitation that took them directly to the online survey. No identifiers were collected and consent to participate was indicated through clicking the submit button at the end of the survey.

\subsection{Measures}

The Moral Distress Scale Revised for Occupational Therapists [Adult Settings] (MDS-R-OT[A]) [2], and the Brief Resilience Scale (BRS) [17], each of which has been empirically validated, were used to measure the selected constructs. The authors of the MDS-R-OT [A] report a content validity index of $81.8 \%$ [2]. The MDS-R-OT [A] contains 21 clinical situation scenarios that were developed using a rigorous methodology to ensure they accurately reflect occupational therapy practice [2]. Respondents were asked to rate the frequency with which they encountered each situation and the level of distress it caused or would cause if experienced. Respondents were encouraged to add and rate one or two of their own personal situations and experiences of moral distress. The moral distress level was calculated by taking the level of disturbance score for each of the 21 situations and multiplying it by the corresponding frequency score. Each individual item score can range from one to 16 . The overall composite moral distress score is calculated by summing the product for each of the 21 situations. The final score can range from 0 to 336, with a possible upper score of 368 if the respondent adds his or her personal experience [18]. Low total scores represent low moral distress, whereas higher scores represent high moral distress. The scale concludes with two questions asking participants whether they have either left a job due to moral distress or have contemplated doing so.

The BRS is a self-report tool that assesses the ability to bounce back from adversity or recover positively from stress. Its factor structure, reliability, convergent and discriminant predictive validity have been demonstrated [17]. The developers report good internal consistency for four different sample, with Cronbach's alpha ranging from 0.80-0.91 (Samples $1-4=0.84,0.87,0.80,0.91$, respectively) [17]. In the BRS respondents were asked to indicate the extent to which they agree with six statements using a five-point scale $(1=$ strongly disagree, to $5=$ strongly agree). the average of responses on all questions. The scale developers suggest that a mean score below 3.00 be considered low, and a score above 4.30 be considered high resilience. The overall average resilience score for the population used to test the scale $(\mathrm{N}=844)$, which included healthy college students, healthy women, women with fibromyalgia, cardiac patients (mostly male), at-risk first generation college students, and urban firefighters was 3.7 [19].

\subsection{Analysis}

Data were entered into SPSS version 24 for descriptive statistical analysis. The small sample size precluded reliable correlation between moral distress and resilience levels, and no calculations beyond descriptive tallies, means, and ranking were carried out. 


\section{Results}

\subsection{Demographics}

Seventy-nine surveys from practicing occupational therapists were returned. We could not determine a definitive response rate because of the snow-ball recruitment method. However, if we assume that no snow-ball effect occurred, and only the SSOT (Saskatchewan) and SAOT (Alberta) members who received the survey participated, then the response rate was $\sim 9-10 \%$. Accordingly the results were not presented as representative of the population. All but four participants were female (94.9\%), 50\% were under 39 years of age, and they worked in a range of settings with a diverse population (see Table 1 for details).

Table 1. Demographics.

\begin{tabular}{|c|c|c|}
\hline Gender \% (N) & Female 94.9 (75) & Male $5.1(4)$ \\
\hline \multirow{5}{*}{ Years of age } & $20-29$ & $25.3(20)$ \\
\hline & $30-39$ & $30.4(24)$ \\
\hline & $40-49$ & $22.8(18)$ \\
\hline & $50-59$ & $13.9(11)$ \\
\hline & $60+$ & $7.6(6)$ \\
\hline \multirow{3}{*}{ Workplace } & Community 26.6 (21) & Long term care 25.3 (20) \\
\hline & School 15.2 (12) & Private practice $13.9(11)$ \\
\hline & Hospital 10.1 (8) & Other $8.9(7)$ \\
\hline \multirow{3}{*}{ Client groups } & Older adult 34.2 (27) & Pediatric 25.3 (20) \\
\hline & Mixed ages 20.3 (16) & Adults 15.2 (12) \\
\hline & No client contact 5.1 (4) & - \\
\hline
\end{tabular}

\subsection{Brief Resiliency Scale}

On the BRS, the mean score was 3.32 (range 1.67-5) with a standard deviation of 0.81 and variance of 0.66 . This score fell to the lower end of normal resiliency as defined by the BRS [17]. Table 2 shows the BRS scores in relation to the findings of a similar study of occupational therapists carried out by Smith et al. [18].

Table 2. Brief resilience scale results.

\begin{tabular}{cccc}
\hline & Mean Score (SD) & Range & Comparison \\
\hline Smith (2013) & $3.7(.68)$ & $3.2-4.0$ & Recommended normal range: $3.0-4.3$ \\
\hline Current Study & $3.32(.81)$ & $1.67-5.0$ & Lower range of normal resilience \\
\hline
\end{tabular}

\subsection{Moral Distress Scale Revised for Occupational Therapists}

The mean MDS-R-OT [A] score was 68.08, and the 10 situations from the scale for which respondents reported the highest levels of moral distress are listed in Table 3. They relate to issues of time, deteriorated quality of care, insensitive co-workers, and unrealistic expectations from others (Table 3). On the MDS-R-OT [A] 49\% reported that they had considered leaving a position due to moral distress, $40 \%$ reported having actually left, and $24 \%$ reported currently considering leaving. 
Table 3. MDS-R-OT [A] score and top ten scored situations reported to cause moral distress.

\begin{tabular}{|c|c|}
\hline \multicolumn{2}{|l|}{ Mean Score 68.08 (Median 72.00, Standard Deviation 45.02, Range 3-198 = 195, N = 79) } \\
\hline MDS-R-OT[A] Situation Most Highly Scored & $\%(\mathrm{~N})$ \\
\hline Expected to treat and/or write documentation for more clients than time allows & $53.3(54)$ \\
\hline Watch the quality of client care suffer due to lack of follow through with recommendations from therapy & $43.3(39)$ \\
\hline Work with healthcare team members who demonstrate insensitivity towards clients, families, or staff & $35.6(32)$ \\
\hline Expected to follow unrealistic directives from the administration that impacts the quality of client care & $30.0(27)$ \\
\hline Witness diminished quality of care due to poor team communication & $27.8(25)$ \\
\hline $\begin{array}{c}\text { Required to care for clients I don't feel qualified to care for or have not received the required advanced } \\
\text { training to provide }\end{array}$ & $18.9(17)$ \\
\hline $\begin{array}{c}\text { Work with team members or healthcare providers who are not as competent or experienced as patient care } \\
\text { requires }\end{array}$ & $18.9(17)$ \\
\hline Carry out physician's orders for what I consider to be unnecessary evaluations or treatments & $15.6(14)$ \\
\hline Unable to provide optimal therapy services to clients due to limited insurance coverage or insurance cutoffs & $14.1(11)$ \\
\hline $\begin{array}{c}\text { Provide services that do not fall within my scope of practice due to staff shortages in other areas or } \\
\text { disciplines }\end{array}$ & $12.2(11)$ \\
\hline
\end{tabular}

\section{Discussion}

The mean MDS-R-OT [A] score of 68.08 (Table 3) demonstrates that moral distress occurred among the occupational therapists included in this study. As this exact version of the MDS has not been used with other populations of healthcare providers, therefore, no direct comparisons can be made. However, Penny et al. used a very similar scale to measure moral distress in a national sample of American occupational therapists $(\mathrm{N}=224)$, and reported a mean score of 50.63 [20]. Perhaps more interestingly, and certainly most helpful in the development of the teaching module that was informed by this study, was the list of situations within the MDS-R-OT[A] scale for which respondents reported the highest levels of moral distress (Table 3). These results provide an indication of the impact of specific workplace policies and culture on the moral distress of participants, and provide guidance in the selection and development of recommendations.

Especially concerning, however, were the responses relating to participants' intentions to leave the organization. On the MDS-R-OT [A] 49\% reported that they had considered leaving a position due to moral distress, $40 \%$ reported had actually left, and $24 \%$ reported currently considering leaving, compared to $20 \%, 25 \%$, and $10 \%$ respectively in the Penny study [20]. The results of this study suggest reason for concern regarding the moral distress experienced by occupational therapists practicing in these two Canadian provinces. Equally worrisome is their relatively low mean resilience score. By definition, moral distress is a relational experience that is shaped by the contexts in which it occurs. As such, attention to both individual and contextual characteristics and processes that enhance resilience in health care environments is warranted. Analysis of the participants' answers to the open ended questions included in our survey, combined with an extensive review of the healthcare literature pertaining to moral distress, provided strategies that both individual healthcare providers, and the organizations in which they work, can put into place to enhance resilience.

Professional resilience enables occupational therapists, and indeed all healthcare practitioners, to persevere through difficult times by using challenges and adversity as catalysts for individual growth, and for positive action. Activities that assist healthcare professionals in cultivating resilience include: taking time for self-reflection, focusing on the purpose and meaning of one's work, documenting one's achievements, maintaining and improving one's professional skills and competencies, and acting on one's intuition and professional values rather than deferring to contextual pressures [7]. The latter sometimes involves taking risks but is particularly useful in managing the uncontrollable parts of one's job, and can help them move towards being energetic, engaged, and feeling efficacious [21]. Indeed, taking initiative, asserting one's professional role, and offering solutions to challenges can engender both personal and organizational growth. Finally, and perhaps most importantly, a strong professional 
identity has been shown to sustain and enhance resilience [22,23]. For this reason, a list of concrete actions that individual occupational therapists can take to assist them in nurturing their professional identity was developed for inclusion in the educational module related to this project and is included here [24] (See Table 4).

Table 4. Actions to build professional identity and resilience.

- $\quad$ Learn more about, and develop skills to address, moral distress and resiliency through resources such as OT Bounce. https://cbotlabs.wixsite.com/ot-bounce

- Use your occupational therapy practice models and frameworks.

- Maintain and improve your professional skills and competencies-reflect on and learn from practice and from other practitioners.

- $\quad$ Seek quality professional supervision—enhances professional reasoning and maintains professional integrity.

- Avoid professional isolation-actively seek out professional mentors and/or networks for guidance and support. Contact your local professional association for details about what is available.

- Develop a professional cluster outside your immediate work area-for both validation and as a sounding board.

- Become more reflective-reflect on challenges and opportunities, examine your strengths, nurture confidence in your abilities, view failure as a learning opportunity. Resources such as the Alberta College of Occupational Therapists video series on reflective practice https:/ / www.youtube.com/watch?v=q6wg3_lgR-Q can be helpful for this.

- Don't cede your locus of control over your practice choices and decisions.

- Take risks - seize challenges and opportunities as they arise to positively contribute to quality patient care and to construct better workplaces.

- Assertively seek out the organizational supports and conditions required to protect your own well-being in your job. Learning about occupational health and safety legislation as it applies to your rights to a healthy workplace can be a good start.

- $\quad$ Achieve life balance, i.e., seek out activities that are physically, emotionally, and spiritually nurturing.

- Maintain a sense of humor: having a good belly laugh is therapeutic!

- Know when to move on to another position-e.g., when facing insurmountable challenges or unable to change the negative features of your job

Professional identity for occupational therapists, however, can be negatively influenced by the context in which they habitually work, for example, those dominated by biomedical models and, for therapists working in mental health, where psychological theories such as dialectical behavioral therapy or cognitive behavioral therapy [22] predominate. In addition, program management structures and case management models of service, that often require health practitioners to work outside their professional domain, can cause professional isolation and blur professional roles, each of which can be challenging to professional identity [20,22]. Frequently being in the minority on health teams, occupational therapists most often report to colleagues from other disciplines who may not understand their professional standards or share their practice perspective [22]. In an examination of this scenario, Fortune concluded that when occupational therapists adopt roles dictated by managers and colleagues who have no knowledge of the occupational therapy treatment paradigm, it places them at risk of identity confusion [25]. Evidence from studies in nursing has demonstrated the negative psychological effects of top down decision-making, limited autonomy, inter-professional antagonism, and professional invalidation, which are surely also relevant to occupational therapists and other healthcare disciplines [7]. This invokes the responsibility that organizations have with regard to the implementation of policies and procedures that foster resilience-building environments.

Many of the avenues to individual resilience discussed in the previous section require a workplace culture that recognizes, supports, and promotes ethical professional practice, and implements resilience-building institutional policies and human resource management principles.

Table 5 lists recommendations, categorized as they relate to the ways professional practice leaders, supervisors/managers, and employers/policy makers/government, respectively, which can contribute 
to the construction of resiliency promoting work environments. Of course, educators, accrediting bodies, professional and regulatory bodies, and researchers also have roles to play, but their discussion is beyond the scope of this paper. Persons interested in these are encouraged to visit the on-line educational module that was developed for occupational therapy students and practitioners upon completion of this study and placed in the public domain [24].

Table 5. Recommendations for building resiliency.

\section{Professional Practice Leaders}

- Work with management and other practice leaders to cultivate practice environments that facilitate (rather than interfere with) the operationalization of professional regulatory practice standards, such as client-centered and evidence-based practice, and codes of ethics.

- $\quad$ Provide role modeling, mentoring, and positive coaching to occupational therapy students and colleagues (particularly persons in the early stages of their career)—share insights from adversity with both students and life-long learners.

- Establish continuing professional development opportunities such that therapists maintain and improve the skills to provide appropriate and safe services-promotes professional identity, self-efficacy, and resilience. These resources are often available free, or at very low rates, through local professional associations or university occupational therapy education programs.

- $\quad$ Provide profession-specific feedback—acknowledge and recognize invested effort.

- Facilitate a positive workplace environment for the sharing of clinical experiences and reflective practice-build positive, nurturing professional relationships.

- Work with managers to build a culture that is attentive to personal health and well-being-including promoting self-care and providing time for reflexive practice. For example, resources specifically designed to educate and build skills for psychological safety and wellbeing in the occupational therapy workplace (e.g., http:/ / cbotlabs.wixsite.com/psychhealthotwork) can be very helpful.

\section{Supervisors/Managers}

Formal leadership support is critical-the biggest impact on an employee's experience of work is related to their supervisor. Guidelines for leaders include:

- Design supervision structures and processes that provide a safe environment in which all staff can reflect on their professional practice. This helps develop a repertoire of problem-solving and coping styles and engenders a goal-oriented perspective.

- Ensure sustainable workloads in order to avoid fatigue and provide opportunities to use and refine existing skills as well as to become effective in emerging areas of activity. Resources such as the Caseload Management Planning Tool (https:/ / www.caot.ca/client/product2/44/itemFromIndex.html) provided free of charge to Canadian Association of Occupational Therapists members, can be a good starting point.

- $\quad$ Provide opportunities and time to develop clinical, management, and leadership skills necessary for employees' future success.

- $\quad$ Equalize power dynamics —engage in inclusive, participative decision-making; include occupational therapists in program planning and resource allocation activities.

- Establish inter-professional guidelines-promote collaboration among ALL members of the health care team ensuring strong communication.

- $\quad$ Provide access to resources and experiences that contribute to individual fulfillment and work engagement.

- Ensure procedural fairness-communicates respect, confirms self-worth, and nurtures professional efficacy.

Employers/Policy-makers/Government

- $\quad$ Ensure vigilance with regard to evolving work demands and new roles associated with socio-economic changes, and administrative and institutional demands.

- Develop benchmarks for key indicators such as patient outcomes and staff turnover as they relate to moral distress and burnout.

- Mandate healthcare organizations to develop policy through an ethical lens by always asking, "What impact will this policy have on the integrity of health care professionals who work within it?"

- Engage professional associations in recognizing and addressing the negative consequences of moral distress and burnout, and the importance of professional resilience in their mitigation. 
This was a small descriptive study, and no definitive statistical conclusions can be drawn. There was an underrepresentation of males responding to the study, the snow-ball recruitment method may have introduced bias, and we cannot claim that a representative sample was achieved. Furthermore, there are possibly regional differences between the two provinces (both are agricultural and energy based economies) that would impact factors, such as regional healthcare budget, that in turn influence moral distress in the workplace. While the diverse sample demographics created some limitations it was also a potential advantage that the participants were from a range of ages and workplace situations so as to demonstrate proof of principle. These exploratory results support the notion that moral distress and resiliency education and strategy development for therapists and students in the occupational therapy workplace is important and that more research is warranted.

\section{Conclusions}

These findings suggest that moral distress exists for occupational therapists working in the Canadian prairie provinces of Alberta and Saskatchewan. The findings also suggest that there are certain morally distressing events and experiences that are more commonly encountered. These findings give some direction for educational and organizational interventions, but much remains unknown and larger studies are required.

A healthy workforce is pivotal to effective healthcare service delivery [26,27]. However, as long as suffering, mortality, and social inequality remain components of the human condition healthcare providers are at risk of experiencing moral distress [5]. Consequences of moral distress include damage to the psychological health of individuals, increased turnover within organizations with all the negative consequences that entails, and attrition within health professions, which present a possible risk to patients and co-workers. While individual occupational therapists, and all healthcare professionals, must take an active role in managing the inherent difficulties in their day-to-day practice, the role of management in fostering resiliency in current healthcare environments must also be addressed. The small study described in this paper informed the development of a web-based education module [24] that describes moral distress and provides extensive information about the many ways in which individual healthcare professionals can cultivate their own resilience, as well as actions that healthcare organizations can take to promote workplace resilience.

Author Contributions: Conceptualization, A.M.R. and C.A.B.; formal analysis, A.M.R. and C.A.B.; funding acquisition, C.A.B.; investigation, C.A.B.; methodology, C.A.B.; writing-original draft preparation, A.M.R.; writing-review and editing, C.A.B.

Funding: This project was partially funded by the Occupational Health and Safety, Innovation and Engagement (OHS I\&E) Grant Program, Government of Alberta, grant number [UofA RES0036338].

Acknowledgments: The authors would like to thank all of the occupational therapists and occupational therapy students who contributed to this project.

Conflicts of Interest: The authors declare no conflicts of interest. The funders had no role in the design of the study; in the collection, analyses, or interpretation of data; in the writing of the manuscript, or in the decision to publish the results.

\section{References}

1. Hunsaker, S.; Chen, H.; Maughan, D.; Heaston, S. Factors that influence the development of compassion fatigue, burnout, and compassion satisfaction in emergency department nurses. J. Nurs. Scholarsh. 2015, 47, 186-194. [CrossRef] [PubMed]

2. Penny, N.H.; Bires, S.J.; Bonn, E.A.; Dockery, A.N.; Pettit, N.L. Moral distress scale for occupational therapists: Part 1. Instrument development and content validity. Am. J. Occup. Ther. 2016, 70. [CrossRef] [PubMed]

3. Rushton, C.H. Cultivating Moral Resilience. Am. J. Nurs. 2017, 117, S11-S15. [CrossRef] [PubMed]

4. Scanlan, J.N.; Still, M. Job satisfaction, burnout, and turnover intention in occupational therapists working in mental health. Aust. Occup. Ther. J. 2013, 60, 310-318. [CrossRef] [PubMed] 
5. Houston, S.; Casanova, M.A.; Leveille, M.; Schmidt, K.L.; Barnes, S.A.; Trungale, K.R.; Fine, R.L. The intensity and frequency of moral distress among different healthcare professionals. J. Clin. Ethics 2013, 24, 98-112. [PubMed]

6. Burnett, H.; Wahl, K. The compassion fatigue and resilience connection: A survey of resilience, compassion fatigue, burnout, and compassion satisfaction among trauma responders. Int. J. Emerg. Ment. Health 2015, 17, 318-326. [CrossRef]

7. McAllister, M.; McKinnon, J. The importance of teaching and learning resilience in the health disciplines: A critical review of the literature. Nurs. Educ. Today 2009, 29, 371-379. [CrossRef] [PubMed]

8. Bushby, K.; Chan, J.; Druif, S.; Ho, K.; Kinsella, E.A. Ethical tensions in occupational therapy: A scoping review. Br. J. Occup. Ther. 2015, 78, 212-221. [CrossRef]

9. Durocher, E.; Kinsella, E.; McCorquodale, L.; Phelan, S. Ethical tensions related to systemic constraints: Occupational alienation in occupational therapy practice. OTJR 2016, 36, 216-226. [CrossRef] [PubMed]

10. Ray, S.L.; Wong, C.; White, D.; Heaslip, K. Compassion Satisfaction, Compassion Fatigue, Worklife Conditions, and Burnout Among Frontline Mental Health Care Professionals. Traumatology 2013, 19, $255-267$. [CrossRef]

11. Pauly, B.; Varcoe, C.; Storch, J. Framing the issues: Moral distress in health care. HEC Forum 2012, $24,1-11$. [CrossRef] [PubMed]

12. Wressle, E.; Samuelsson, K. High job demands and lack of time: A future challenge in occupational therapy. Scand. J. Occup. Ther. 2013, 21, 421-428. [CrossRef] [PubMed]

13. Kinsella, E.A.; Park, A.J.; Appiagyei, J.; Chang, E.; Chow, D. Through the eyes of students: Ethical tensions in occupational therapy practice. Can. J. Occup. Ther. 2008, 75, 176-183. [CrossRef] [PubMed]

14. Leiter, M.; Maslach, C. Areas of worklife: A structured approach to organizational predictors of job burnout. Res. Occup. Stress Wellbeing 2004, 3, 91-134.

15. Wagnild, G. True Resilience: Building a Life of Strength, Courage, and Meaning; Cape House Publishing: Cape May, NJ, USA, 2014.

16. Canadian Institute for Health Information. Available online: www.cihi.ca (accessed on 1 October 2018).

17. Smith, B.W.; Dalen, J.; Wiggins, K.; Tooley, E.; Christopher, P.; Bernard, J. The brief resilience scale: Assessing the ability to bounce back. Int. J. Behav. Med. 2008, 15, 194-200. [CrossRef] [PubMed]

18. Hamric, A.; Borchers, C.; Epstein, E. Development and testing of an instrument to measure moral distress in healthcare professionals. AJOB Prim. Res. 2012, 3, 1-9. [CrossRef]

19. Smith, B.W.; Epstein, E.M.; Ortiz, J.A.; Christopher, P.J.; Tooley, E.M. The Foundations of Resilience: What Are the Critical Resources for Bouncing Back from Stress? Springer Science + Business Media: New York, NY, USA, 2013.

20. Penny, N.H.; Ewing, T.L.; Hamid, R.C.; Shutt, K.A.; Walter, A.S. An Investigation of Moral Distress Experienced by Occupational Therapists. Occup. Ther. Health Care 2014, 28, 382-393. [CrossRef] [PubMed]

21. Westmorland, M. Risk taking: An antidote to diffidence. Can. J. Occup. Ther. 1999, 66, 214-219. [CrossRef] [PubMed]

22. Ashby, S.E.; Ryan, S.; Gray, M.; James, C. Factors that influence the professional resilience of occupational therapists in mental health practice. Aust. Occup. Ther. J. 2013, 60, 110-119. [CrossRef] [PubMed]

23. Nolan, E.; Hewison, A. Teamwork in primary care mental health: A policy analysis. J. Nurs. Manag. 2008, 16, 649-661. [CrossRef] [PubMed]

24. OTBounce. 2018. Available online: https://cbotlabs.wixsite.com/ot-bounce (accessed on 1 October 2018).

25. Fortune, T. Occupational Therapists: Is our therapy truly occupational or are we merely filling gaps? Br. J. Occup. Ther. 2000, 63, 225-230. [CrossRef]

26. Poulsen, A.; Meredith, P.; Khan, A.; Henderson, J.; Castrisos, V.; Khan, S. Burnout and work engagement in occupational therapists. Br. J. Occup. Ther. 2013, 7, 156-164. [CrossRef]

27. Jackson, D.; Firtko, A.; Edenborough, M. Personal resilience as a strategy for surviving and thriving in the face of work adversity: A literature review. J. Adv. Nurs. 2007, 60, 1-9. [CrossRef] [PubMed]

(C) 2019 by the authors. Licensee MDPI, Basel, Switzerland. This article is an open access article distributed under the terms and conditions of the Creative Commons Attribution (CC BY) license (http:/ / creativecommons.org/licenses/by/4.0/). 